\title{
Clarifying the concepts of joy and meaning for work in health care
}

\author{
Alden Yuanhong Lai ${ }^{1} \wedge$, Bram P. I. Fleuren ${ }^{2} \wedge$ \\ ${ }^{1}$ Department of Public Health Policy and Management, New York University School of Global Public Health, New York, NY, USA; ${ }^{2}$ Department of \\ Work and Social Psychology, Faculty of Psychology and Neuroscience, Maastricht University, Maastricht, The Netherlands \\ Correspondence to: Alden Yuanhong Lai, PhD, MPH. New York University School of Global Public Health, 708 Broadway, 7th floor, \#734, New York, \\ NY 10003, USA. Email: aldenlai@nyu.edu.
}

Received: 11 March 2021; Accepted: 30 April 2021; Published: 25 March 2022.

doi: 10.21037/jhmhp-21-22

View this article at: http://dx.doi.org/10.21037/jhmhp-21-22

The wellbeing of health care workers is a prime concern in the functioning and performance of health care organizations. While the Triple Aim-enhancing patient experience, improving population health, and reducing health care costs-has contributed to health system reforms worldwide, scholars have asserted the need for a fourth aim to improve the professional lives of health care workers (1). Such improvements promote work engagement, job satisfaction, and talent retention; protect against the increasingly prevalent phenomenon of burnout among clinicians; and are essential for the quality and safety of care (2). They prompt health care leaders and managers to pay more attention to issues such as physicians' experiences of autonomy loss and stress related to malpractice liability, as well as nurses' experiences of disrespectful behaviors at work for example. More specifically, the Quadruple Aim is a call to help health care workers restore and maintain "joy and meaning in work" (3). Similarly, the Institute for Healthcare Improvement has promoted joy in work as a goal for organizations to work towards (4).

The concepts of joy and meaning can however be elusive when health care leaders and managers seek to implement and evaluate workplace interventions to increase workplace wellbeing. This is because both concepts are used and defined in everyday discourse in a myriad of ways, including as a state of being, as a process of self-transcendence, or in relation to spiritual beliefs (5). Not only do these definitions preclude a consistency in which health care leaders and managers approach joy and meaning at work, there is also a wide array of conceptual definitions for and instruments to measure joy and meaning in the scientific literature (6).
To make the concepts of joy and meaning in work more relevant to the health care context, we highlight some key insights from psychological research via a concept analysis in this paper. We first discuss the definitions of both concepts and how they relate to wellbeing at work more broadly. We then distinguish the nuances between (I) joy and meaning in and at work, and (II) meaning and meaningfulness. Finally, we discuss how health care workers can achieve meaningfulness through having an impact on others, workplace relationships, and professional development. By elaborating these concepts as well as their antecedents, we aim to highlight some dimensions that health care leaders and managers should consider when improving the wellbeing of health care workers.

\section{Defining joy and meaning}

\section{foy}

The Oxford Dictionary defines joy as an emotional state, namely "a feeling of great pleasure and happiness" (7). This definition is rooted in hedonic wellbeing, presenting joy as a pleasurable state of being. Some scholars have also defined joy beyond the hedonistic tradition. For example, Manion studied clinicians and their perspectives on the nature of joy, concluding it as "an intensely positive, vivid, and expansive emotion that arises from an internal state or results from an external event or situation. It may include a physiologic reaction, an expressive component, and conscious volition. It is a transcendent state of heightened energy and excitement (8)". Similarly, Fredrickson, whose

^ ORCID: Alden Yuanhong Lai, 0000-0002-2416-2915; Bram P. I. Fleuren, 0000-0002-9748-2522. 
work is among the most widely cited in and outside the field of psychology, discusses joy as a positive emotion that can widen "the array of the thoughts and actions that come to mind" (9). These definitions align with the functionalist perspective on emotions (i.e., feeling is for doing), which suggests joy as an emotional state that motivates people into particular actions (10).

It is therefore unsurprising that joy has been linked to various forms of action at work in health care. Sinsky et al. positioned joy in the practice of primary care as engaging in particular innovative arrangements related to health information technology, clinical workflow, and teamwork (11). Similarly, other researchers have found that certain conditions such as the absence of time pressure, job content, and working climate predict the joy that underlie the completion of work tasks (12). This perspective implies a responsibility for health care leaders and managers to consider joy as a motivator for desired work behaviors, in addition to commonly used incentives such as pay-for-performance measures (4).

\section{Meaning and meaningfulness}

Meanings are a set of interpretations that people use to make sense of the world, and they can be neutral, negative or positive (13). Meaningfulness, on the other hand, refers to the intensity and significance of meanings, and is inherently positive and personally relevant (13). The meaningfulness that health care workers ascribe to particular aspects of their work shape how significant and positive they personally experience work as (14). Meaningfulness creates the psychological experience in which a health care worker feels that they are "made for this job," or are fulfilling their various callings through work. For example, Shanafelt et al. described how physicians often value being a healer, teacher, scientist, or domain expert (15). Meaningfulness is thus associated with the concept of eudaimonia ( $v s$. hedonic) wellbeing (16), because it orients towards purpose rather than pleasure.

\section{Foy and meaningfulness in and at work}

It is important to distinguish between characteristics of the work itself (i.e., joy/meaning in work) and the context in which work takes place (i.e., joy/meaning at work) (14). This is because the former leads leaders and managers to emphasize more on what it means to belong to a particular profession/role, while the latter relates to what it means to belong to a particular team, unit, or organization. For example, the meaning in work will resonate more than the meaning at work among medical residents, since they typically perceive their role in a health care organization as preparation for a "real" career (17). Conversely, the meaning at work will resonate more among health care workers with long tenures who strongly identify as a member of their employing organization.

\section{Pathways to meaningfulness: contribution, unification, and individuation}

Central in understanding the meaningfulness in/at work is health care workers' intrapsychic responses to the question, "Why am I here?" (18). Scholars have identified at least three clusters of responses to this question: contribution, unification, and individuation $(13,18)$. First, the contribution pathway to meaningfulness encompasses responses like "to have a significant positive impact on others" (18). Here, meaningfulness is achieved through one's work impact on others or the environment. Second, the unification pathway covers responses such as "to engage and connect with others around me" (18). In unification, meaningfulness is built on cultivated relationships with patients, patients' family, coworkers, and so forth. Lastly, the individuation pathway corresponds to responses such as "to engage in my own professional growth" (18). Individuation refers to selfdevelopment as a way to make work meaningful. It involves acts of advancement surrounding one's chosen professional role(s) and domain(s).

The contribution, unification, and individuation pathways can be facilitated in health care organizations. The contribution pathway is arguably the most prevalent way in which health care workers generate meaningfulness. Many health care workers interact with patients, and see a part of their jobs as "saving lives"- a systematic review on health care students' reasons for their career choices found that they are predominantly motivated by the altruistic desire to help others (19). To use this pathway, health care leaders and managers can, for example, incorporate patient feedback during the annual review process to explicitly recognize the contributions and differences that an individual worker may have made for particular patients in the preceding year (20). Secondly, unification can occur particularly through team-based care models, but also through building connections with patients and their caregivers. A related theoretical perspective, job crafting, predicts that health care workers adapt their working relationships with others to create more meaningful work 
experiences (21). Health care leaders and managers may therefore consider paying more attention in communicating their expectations with individual workers on the extent to which they are able to craft their relationships with others at work. For example, this may include leaders and managers acknowledging health care workers' ability, or giving them permission, to invite coworkers in other departments to serve as additional mentors. Lastly, health care leaders and managers can facilitate individuation by structuring and offering opportunities for vertical as well as horizontal promotions. This pathway is particularly accessible to health care workers with pre-defined career milestones and specialization opportunities such as doctors, nurses, pharmacists, and therapists.

Notably, the ways of achieving meaningfulness in and at work are not mutually exclusive. A thematic analysis of doctors' narratives about their meaningful experiences collected over seven years showed elements of all three pathways (22). A similar national study with nurses showed unification and individuation as two prominent themes (23). It is further plausible that there is a temporal effect to these pathways. For example, the individuation pathway may be the strongest when people initially decide to seek a career in health care and/or are in training. However, the unification pathway may then supersede individuation when people are embedded in their work environments for longer periods of time and with designated work teams.

\section{Work values-environment fit}

The aforementioned pathways point to several commonly recognized work conditions that health care leaders and managers can alter, but the notion of work values and environmental fit deserves attention in the context of joy and meaningfulness (6). While opportunities to make a difference in patients' lives, foster coworker relationships, and develop professionally contribute to meaningfulness, recognizing the extent to which health care workers personally value these aspects is important. For example, some health care workers may be less concerned with professional development, but more with having positive relationships with coworkers. Others may focus on salaries, or the patient population they are serving. The extent to which work and the work context currently address individuals' values co-determine the meaningfulness that health care workers experience. To improve joy and meaning at work, health care leaders and managers may therefore consider identifying the values that particular worker groups (e.g., staff with more than 10 years of work experience in the organization $v s$. those with less) emphasize the most in order to develop more targeted approaches based on each of the pathways (24).

\section{Conclusions}

With the Quadruple Aim as a guiding framework, restoring and maintaining joy and meaning among workers are undoubtedly significant goals for health care organizations. Yet, the concepts of joy and meaning can remain elusive for health care leaders and managers. This article elaborates on these concepts as well as some of their related antecedents. Although we have highlighted three pathways to achieve meaning at/in work among health care workers, leaders and managers should be aware of preserving a fit between employees' work values and what the organization offers. These notions align with Leape et al.'s statement on the principles needed to systematically improve care quality and safety: "capturing the soul of an organization, where joy and meaning resides, requires a true partnership to align values among organization leaders, professionals, and the workforce" (25). Such partnerships, however, first require clarification of the definitions and pathways related to joy and meaningfulness that can/should be targeted among health care workers. It is then when you can create highfunctioning health systems whose souls we ought to capture.

\section{Acknowledgments}

The authors would like to thank Tim Lomas for providing helpful comments on an earlier draft of the manuscript. Funding: None.

\section{Footnote}

Provenance and Peer Review: This article was a standard submission to the journal. The article has undergone external peer review.

Conflict of Interests: Both authors have completed the ICMJE uniform disclosure form available at https://jhmhp. amegroups.com/article/view/10.21037/jhmhp-21-22/coif). The authors have no conflicts of interest to declare.

Ethical Statement: The authors are accountable for all aspects of the work in ensuring that questions related to the accuracy or integrity of any part of the work are 
appropriately investigated and resolved.

Open Access Statement: This is an Open Access article distributed in accordance with the Creative Commons Attribution-NonCommercial-NoDerivs 4.0 International License (CC BY-NC-ND 4.0), which permits the noncommercial replication and distribution of the article with the strict proviso that no changes or edits are made and the original work is properly cited (including links to both the formal publication through the relevant DOI and the license). See: https://creativecommons.org/licenses/by-nc-nd/4.0/.

\section{References}

1. Sikka R, Morath JM, Leape L. The Quadruple Aim: care, health, cost and meaning in work. BMJ Qual Saf 2015;24:608-10.

2. National Academies of Sciences, Engineering, and Medicine; National Academy of Medicine; Committee on Systems Approaches to Improve Patient Care by Supporting Clinician Well-Being. Taking Action Against Clinician Burnout: A Systems Approach to Professional Well-Being. Washington (DC): National Academies Press (US), 2019.

3. Lucian Leape Institute. Through the eyes of the workforce: creating joy, meaning, and safer health care. MA: National Patient Safety Foundation, 2013.

4. Perlo J, Balik B, Swensen S, et al. IHI framework for improving joy in work. Cambridge, Massachusetts: Institute for Healthcare Improvement, 2017.

5. Burton N. What is the meaning of life? Psychology Today. 2018. Accessed October 15 2019. Available online: https://www.psychologytoday.com/us/blog/hide-andseek/201803/what-is-the-meaning-life

6. Both-Nwabuwe JMC, Dijkstra MTM, Beersma B. Sweeping the Floor or Putting a Man on the Moon: How to Define and Measure Meaningful Work. Front Psychol 2017;8:1658.

7. Lexico.com2020. Definition of joy. Accessed April 62021. Available online: https://www.lexico.com/ definition/joy

8. Manion J. Joy at work! : creating a positive workplace. J Nurs Adm 2003;33:652-9.

9. Fredrickson BL. The role of positive emotions in positive psychology. The broaden-and-build theory of positive emotions. Am Psychol 2001;56:218-26.

10. Higgins ET. Value from hedonic experience and engagement. Psychol Rev 2006;113:439-60.

11. Sinsky CA, Willard-Grace R, Schutzbank AM, et al. In search of joy in practice: a report of 23 high-functioning primary care practices. Ann Fam Med 2013;11:272-8.

12. Schröder C, Bänsch A, Schröder H. Work and health conditions of nursing staff in palliative care and hospices in Germany. Psychosoc Med 2004;1:Doc08.

13. Rosso BD, Dekas KH, Wrzesniewski A. On the meaning of work: a theoretical integration and review. Res Organ Behav 2010;30:91-127.

14. Pratt MG, Ashforth BE. Fostering meaningfulness in working and at work. In: Cameron TKS, Dutton JE, Quinn RE, editors. Positive organizational scholarship: Foundations of a new discipline, 2003:309-27.

15. Shanafelt T, Chung H, White H, et al. Shaping your career to maximize personal satisfaction in the practice of oncology. J Clin Oncol 2006;24:4020-6.

16. Steger MF, Dik BJ, Duffy RD. Measuring meaningful work: The work and meaning inventory (WAMI). J Career Assess 2012;20:322-37.

17. Brady DW, Corbie-Smith G, Branch WT. "What's important to you?" The use of narratives to promote selfreflection and to understand the experiences of medical residents. Ann Intern Med 2002;137:220-3.

18. Robertson KM, O'Reilly J, Hannah DR. Finding meaning in relationships: The impact of network ties and structure on the meaningfulness of work. Online First. Acad Manage Rev 2019;45:596-619.

19. Wu LT, Low MM, Tan KK, et al. Why not nursing? A systematic review of factors influencing career choice among healthcare students. Int Nurs Rev 2015;62:547-62.

20. Shanafelt T, Swensen S. Leadership and physician burnout: using the annual review to reduce burnout and promote engagement. Am J Med Qual 2017;32:563-5.

21. Wrzesniewski A, Dutton JE. Crafting a Job: revisioning employees as active crafters of their work. Acad Manage Rev 2001;26:179-201.

22. Horowitz CR, Suchman AL, Branch WT Jr, et al. What do doctors find meaningful about their work? Ann Intern Med 2003;138:772-5.

23. Galuska L, Hahn J, Polifroni EC, et al. A narrative analysis of nurses' experiences with meaning and joy in nursing practice. Nurs Adm Q 2018;42:154-63.

24. Abma FI, Brouwer S, de Vries HJ, et al. The capability set for work: development and validation of a new 
questionnaire. Scand J Work Environ Health. 2016;42:34-42.

25. Leape L, Berwick D, Clancy C, et al. Lucian Leape

doi: $10.21037 /$ jhmhp-21-22

Cite this article as: Lai AY, Fleuren BPI. Clarifying the concepts of joy and meaning for work in health care. J Hosp Manag Health Policy 2022;6:9.
Institute at the National Patient Safety Foundation. Transforming healthcare: a safety imperative. Qual Saf Health Care 2009;18:424-8. 